\title{
openheart Mapping the potential of community first responders to increase cardiac arrest survival
}

\author{
Tomás Barry, ${ }^{1}$ Ainhoa González, ${ }^{2}$ Niall Conroy, ${ }^{1}$ Paddy Watters, ${ }^{3}$ \\ Siobhán Masterson, ${ }^{4,5}$ Jan Rigby, ${ }^{6}$ Gerard Bury ${ }^{7}$
}

To cite: Barry T, González A, Conroy $\mathrm{N}$, et al. Mapping the potential of community first responders to increase cardiac arrest survival. Open Heart 2018;5:e000912. doi:10.1136/ openhrt-2018-000912

Received 3 August 2018 Revised 5 September 2018 Accepted 26 September 2018

Check for updates

(C) Author(s) (or their employer(s)) 2018. Re-use permitted under CC BY-NC. No commercial re-use. See rights and permissions. Published by BMJ.

${ }^{1}$ School of Medicine, University College Dublin, Dublin, Ireland ${ }^{2}$ School of Geography, University College Dublin, Dublin, Ireland ${ }^{3}$ National Emergency Operations Centre, National Ambulance Service, Dublin, Ireland ${ }^{4}$ School of Medicine, National University of Ireland Galway, Discipline of General Practice, Galway, Ireland

${ }^{5}$ Out of Hospital Cardiac Arrest Strategy, National Ambulance Service, Dublin, Ireland ${ }^{6}$ Department of Geography, Maynooth University, Maynooth, Ireland

${ }^{7}$ Professor of General Practice, University College Dublin, Dublin, Ireland

Correspondence to Dr Tomás Barry; tomas.barry@ ucd.ie

\section{ABSTRACT}

Objective Resuscitation from out-of-hospital cardiac arrest $(\mathrm{OHCA})$ is largely determined by the availability of cardiopulmonary resuscitation (CPR) and defibrillation within 5-10 min of collapse. The potential contribution of organised groups of volunteers to delivery of CPR and defibrillation in their communities has been little studied. Ireland has extensive networks of such volunteers; this study develops and tests a model to examine the potential impact at national level of these networks on early delivery of care.

Methods A geographical information systems study considering all statutory ambulance resource locations and all centre point locations for community first responder (CFR) schemes that operate in Ireland were undertaken. ESRI ArcGIS Desktop 10.4 was used to map CFR and ambulance base locations. ArcGIS Online proximity analysis function was used to model $5-10$ min drive time response areas under sample peak and off-peak conditions. Response areas were linked to Irish population census data so as to establish the proportion of the population that have the potential to receive a timely cardiac arrest emergency response.

Results This study found that CFRs are present in many communities throughout Ireland and have the potential to reach a million additional citizens before the ambulance service and within a timeframe where CPR and defibrillation are likely to be effective treatments.

Conclusion CFRs have significant potential to contribute to survival following OHCA in Ireland. Further research that examines the processes, experiences and outcomes of CFR involvement in OHCA resuscitation should be a scientific priority.

\section{INTRODUCTION}

Resuscitation from out-of-hospital cardiac arrest (OHCA) is largely determined by the availability of cardiopulmonary resuscitation (CPR) and defibrillation within 5-10 min of collapse. The potential contribution of organised groups of volunteers to delivery of CPR and defibrillation in their communities has been little studied. Ireland has extensive networks of such volunteers; this study develops and tests a model to examine the

\section{Key questions}

What is already known about this subject?

- A small number of studies have demonstrated that under experimental conditions and in specific localised regions, dispatched community first responders (CFRs) can deliver early cardiopulmonary resuscitation (CPR) and defibrillation thus potentially increasing survival following out-of-hospital cardiac arrest (OHCA).

- Despite this potential, research concerning CFRs has received relatively little attention compared with other potential cardiac arrest interventions.

What does this study add?

- This study demonstrates that CFRs have significant potential to reach patients before the ambulance service and thus increase survival following OHCA at national level in Ireland.

How might this impact on clinical practice?

- Health system resources should be directed at exploring, establishing, measuring and optimising CFR involvement in OHCA resuscitation.

potential impact at national level of these networks on early delivery of care.

The Republic of Ireland has a population of 4.7 million distributed across 26 counties. ${ }^{1}$ In Ireland in 2016, there were 2389 cases of OHCA with resuscitation attempted by the ambulance services. ${ }^{2}$ Two-thirds of patients were male, median age was 67 years old and ultimately only $7.8 \%$ of patients survived to hospital discharge. ${ }^{2}$ Key to improving this outcome is the concept of the chain of survival. ${ }^{3}$ The crucial initial links in this chain are early recognition and call for help, immediate CPR and defibrillation within the earliest possible interval following OHCA. ${ }^{4}$ Early CPR and defibrillation are the vital but critically time-sensitive treatments following OHCA. $^{5}$ Each minute of delay to defibrillation reduces the probability of survival by $10 \%-12 \%$, with good quality CPR providing the only hope of preserving the possibility 
of survival while awaiting the arrival of a defibrillator. ${ }^{67}$ In 2016 in Ireland, 84\% of patients who had witnessed OHCA had bystander CPR performed and $20 \%$ of all defibrillation attempts were performed before the ambulance service arrival. ${ }^{2}$

In Ireland, statutory ambulance services are provided by the National Ambulance Service and in the capital also by Dublin Fire Brigade. The Irish Health Information and Quality Authority has set key performance indicators for emergency service response times that state that a patient in cardiac arrest should receive an emergency response within $8 \mathrm{~min}$ in $75 \%$ of all cases. ${ }^{8}$ One-third of OHCA occurs in rural areas. ${ }^{2}$ Data suggest that only $9 \%$ of rural Irish OHCA patients receive a statutory ambulance response in the target timeframe, and furthermore rural OHCA patients are less likely to be discharged alive from hospital than those living in urban areas. ${ }^{9}$ Given the time critical nature of the initial links in the chain of survival and the challenges posed by Ireland's settlement patterns, innovative responses to OHCA such as the deployment of community first responders (CFRs) have been advocated and implemented..$^{111}$

OHCA CFRs are volunteers who live or work within a community and are organised in a framework that offers OHCA care in that community to supplement the standard ambulance service response. ${ }^{12}$ CFRs are activated by text message alert in real time to attend nearby OHCAs in the community by ambulance service dispatch. CFRs have basic life support (BLS) training and are generally equipped with a defibrillator. In Ireland, various types of OHCA CFR exist; these can be broadly divided into two categories. Group CFR schemes are composed of trained lay individuals who provide CFR response in their own local community (lay CFR groups); several dozen people may join any individual scheme. Group CFR schemes also include some county fire service volunteer CFR schemes who fulfil the role of CFR in addition to their fire service statutory duty (fire CFR groups). Individual-based schemes include ambulance service off-duty practitioners (ODPs), general practitioners who participate in the Merit 3 programme (Merit $3 \mathrm{GPs})^{13}$ and other individual responders including a small number of other doctors and health services employees. By their nature, group CFR schemes might be expected to have greater availability to respond around the clock, whereas the availability of individual CFRs depends on their work and other commitments.

Group and individual CFR accreditation occurs through the National Ambulance Service. Responders 'go live' when training, equipment, activation and support structures are in place. Most group CFR schemes operate by having a roster of two-person teams carry a dedicated alert phone, defibrillator and BLS equipment to cover defined periods for their area. When an alert is received, the CFR(s) responds using normal driving rules and contacts ambulance control for updated information when necessary. International research has demonstrated that CFRs have the potential to play a significant role in early CPR, defibrillation and potentially OHCA survival. ${ }^{14-16}$ It has yet to be established whether CFRs can reach a significant proportion of citizens at population level, in advance of the ambulance service and while defibrillation and CPR are likely to remain effective treatments that result in survival. The mobilisation of CFRs to OHCA is a complex community intervention that is not without potential risk. It raises issues around driving and personal safety, medicolegal concerns, professional roles, clinical supervision and the personal impact of participating in what might be emotionally distressing circumstances. ${ }^{151718}$ At present, there are limited data available reporting the activities of CFRs in Ireland or their impact in OHCA care and resultant outcomes. ${ }^{2} 13$

This study uses data on more than 600 operational statutory and volunteer OHCA agencies/responders in Ireland to model their individual and complementary abilities to respond within 5-10 min windows. The primary aim of this study is to model the potential impact of statutory and volunteer responders in OHCA; a secondary aim is to identify those areas/populations that have poor coverage from currently operational resources.

\section{METHODS}

The National Emergency Operations Centre (NEOC) is based over two sites. It coordinates statutory emergency service responses to OHCA and alerts CFRs if available in a given area. NEOC maintains a database of all CFR resources available in Ireland linked with the ambulance service. The NEOC resource dispatch system generates a response area/radius (usually $5-10 \mathrm{~km}$ ) around a fixed geographical centre point for each CFR resource. NEOC use the Advanced Medical Priority Dispatch System to categorise emergency calls and dispatch appropriate resources. When OHCA occurs within a CFR response area, NEOC alert the relevant CFR(s) using mobile phone text message technology. This occurs concurrently with ambulance resource dispatch, and as the process is automated, a text message alert is sent as soon as OHCA is recognised and at times even before an ambulance resource is fully mobilised via conventional radio communication systems.

The model to be tested uses the nominated location of the agency/responder as a starting point and measures the population that can be covered in a 5-10 min drive from that location, under different driving conditions. The incremental population coverage by statutory ambulance services and then volunteer responders is calculated. The mapping and demographic tools used provide the best available estimates of the potential coverage provided by these responders, if continuous availability from that location were possible-an obvious 'real-world' limitation.

For this study, NEOC provided centre point location and categorical data for all CFR resources registered on the NEOC dispatch system in January 2018. Geographical point data for National Ambulance Service base locations 
were obtained from the Health Services Executive, Health Intelligence Unit; Dublin Fire Brigade fire/ambulance station locations were obtained using Google Maps. Census 2016 population data at small area (generally comprising between 80 and 120 dwellings) and electoral division (legacy administrative areas with highly variable populations) level were obtained from the Irish Central Statistics Office. ${ }^{19}$ Small area level is the most detailed level of mapping for which population statistics are available in Ireland, while electoral divisions are the smallest legally defined administrative areas in the Irish state and are included for the purposes of illustrating population density. ${ }^{20}$

ESRI ArcGIS Desktop 10.4 was used to map point locations for statutory ambulance resources and centre point locations for all CFRs registered with the NEOC. ArcGIS Online (AGOL) proximity analysis function was used to model 5 min and 10 min drive time response areas from the mapped base points under sample peak (Tuesday 08:00) and off-peak (Tuesday 04:00) conditions. AGOL's online proximity analysis drive time area function is a commercial geographical information system (GIS) tool that uses an advanced algorithm combining historical and live traffic data from billions of GPS and cell phone probes to compile accurate road travel speeds. ${ }^{21}$ Combined drive time areas were modelled for statutory ambulance service base locations in isolation, with the addition of group CFR schemes and finally with the further incremental addition of all other individual CFRs. ArcGIS Desktop was then used to link the modelled drive time areas with 2016 census population data at small area level.

It was thus possible to model the proportion of the population potentially served by a given CFR, statutory resource or combination of resources within a $5 \mathrm{~min}$ and $10 \mathrm{~min}$ drive time response interval. Where a drive time area boundary enclosed only a portion of a small area, the total population of the relevant small area was included in any relevant calculations. As this was likely to somewhat overestimate population coverage, an additional sensitivity analysis was undertaken that considered a 'proportional enclosed area'-based population calculation for small areas that intersected with drive time area boundaries. Populations not well served by community cardiac arrest resources were identified and examined in terms of population density at the level of electoral district.

The study was approved by the National Ambulance Service Research Committee prior to the initiation of data collection.

\section{RESULTS}

NEOC provided details of 536 valid CFR point coordinates in January 2018. These were combined with 105 coordinates obtained for ambulance base locations giving a total of 641 valid cardiac arrest response resource points (see table 1). Figure 1 illustrates the geographic

\begin{tabular}{|l|l|}
\hline Table $1 \quad$ Irish OHCA response resources \\
\hline Community cardiac arrest resource points & (n=641) \\
\hline Statutory ambulance & 105 \\
\hline Of which & \\
\hline National Ambulance Service base location & 91 \\
\hline Dublin Fire Brigade base location & 14 \\
\hline Community first responder & 536 \\
\hline Of which & \\
\hline Group based & 209 \\
\hline \multicolumn{1}{|c|}{ Lay community group } & 196 \\
\hline County fire service & 13 \\
\hline Independent individual CFRs & 327 \\
\hline \multicolumn{1}{|l}{ Merit general practitioner } & 106 \\
\hline Off-duty practitioner & 205 \\
\hline Other individual & 16 \\
\hline
\end{tabular}

distribution of all resources that can be potentially deployed in the event of OHCA. A magnified section showing Dublin is also included. Over half of all locations represented individual responders, with ambulance

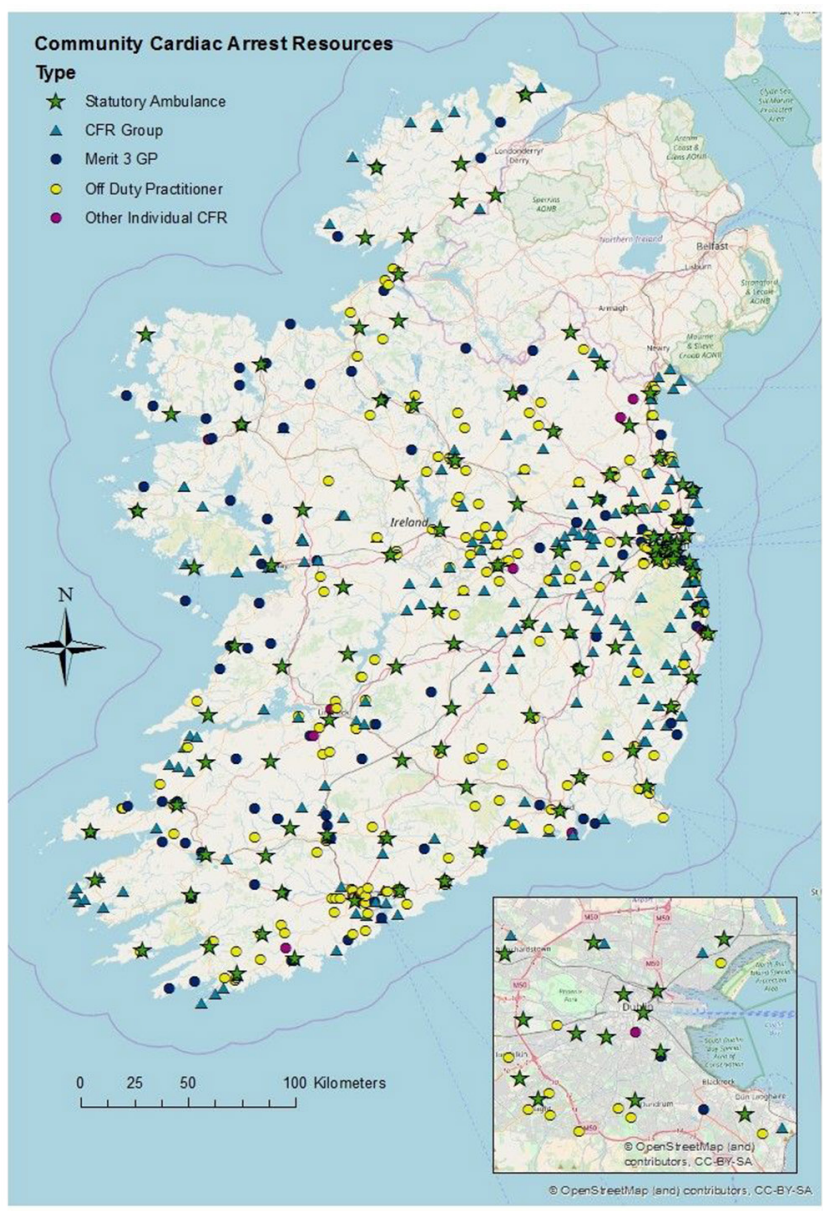

Figure 1 Irish OHCA response resources, geographical distribution. CFR, community first responder; GP, general practitioner; OHCA, out-of-hospital cardiac arrest. 
Table 2 Modelling CFR contribution to community OHCA response

Community OHCA resources, travel times and population cover modelling

Total Irish population 4761865

\begin{tabular}{|c|c|c|c|c|c|}
\hline & Peak & $\%$ total pop & Off peak & $\%$ total pop & $\begin{array}{l}\text { Peak/off-peak difference } \\
\text { (\% total population) }\end{array}$ \\
\hline \multicolumn{6}{|c|}{5 min travel time response zones: population coverage } \\
\hline Statutory ambulance responses & 1480548 & 31.1 & 2065197 & 43.4 & 12.3 \\
\hline $\begin{array}{l}\text { Statutory ambulance with only CFR } \\
\text { group responses }\end{array}$ & 2239360 & 47.0 & 2793457 & 58.7 & 11.7 \\
\hline $\begin{array}{l}\text { Statutory ambulance with all CFR } \\
\text { responses }\end{array}$ & 3088608 & 64.9 & 3530889 & 74.1 & 9.2 \\
\hline \multicolumn{6}{|c|}{10 min travel time response zones: population coverage } \\
\hline Statutory ambulance responses & 2972302 & 62.4 & 3345205 & 70.2 & 7.8 \\
\hline $\begin{array}{l}\text { Statutory ambulance with only CFR } \\
\text { group responses }\end{array}$ & 3790965 & 79.6 & 4032255 & 84.7 & 5.1 \\
\hline $\begin{array}{l}\text { Statutory ambulance with all CFR } \\
\text { responses }\end{array}$ & 4312170 & 90.6 & 4401983 & 92.4 & 1.8 \\
\hline
\end{tabular}

CFR, community first responder; OHCA, out-of-hospital cardiac arrest.

service ODPs representing almost one-third of all point locations. Group-based CFR schemes including lay and fire CFR groups represented a further third of point locations.

Table 2 demonstrates the results of population coverage modelling when 5 min and 10 min cardiac arrest response zones are considered under sample peak and off-peak driving conditions. The model considers statutory ambulance base locations, group CFR scheme centre point locations and individual CFR centre point locations. Table 2 outlines the baseline population covered by the statutory ambulance services and the additional potential populations that can be reached when group CFR schemes and individual CFRs are considered as incremental additional OHCA response resources.

The AGOL model outputs indicate that the statutory ambulance services can reach just over $30 \%$ of the population under peak driving conditions increasing to over $40 \%$ during off-peak traffic conditions within a $5 \mathrm{~min}$ road-based drive time. When all additional CFR resources are considered, the outputs indicate that this rises to $65 \%$ of the population potentially reached in $5 \mathrm{~min}$ at peak driving conditions and $74 \%$ during off-peak traffic conditions. When a $10 \mathrm{~min}$ drive time is considered, the statutory ambulance services can reach over $60 \%$ of the population under peak conditions rising to $70 \%$ during off-peak conditions. When all additional CFR resources are considered, over $90 \%$ of the population can potentially be reached under both peak and off peak conditions, within $10 \mathrm{~min}$. This indicates that over a million extra citizens (representing one-fifth of Ireland's total population) could be reached within both $5 \mathrm{~min}$ and 10 min time frames when CFR resources supplementing the statutory ambulance service OHCA response operate to their full capacity. This finding was sustained when sensitivity analysis considering a 'proportional enclosed area'-based population calculation for boundary small areas was performed (table 3 ).

Figure 2 (section A) is a map showing the potential in terms of $10 \mathrm{~min}$ road travel response zones when only statutory ambulance base locations are modelled, while figure 2 (section $\mathrm{B}$ ) maps the $10 \mathrm{~min}$ response zones when all 536 volunteer responders are added to the statutory responses. Modelling was undertaken under off-peak conditions. figure 2 also illustrates the underlying population density distribution of Ireland at the level of electoral district.

It is evident that a high proportion of the areas outside the 10 min response time are of a low population density; however, some higher population density areas can also be identified. Figure 2 illustrates that without volunteer

Table 3 Sensitivity analysis (area proportional population calculation carried out for boundary small areas)

Travel times and population cover modelling - sensitivity analysis

\begin{tabular}{|c|c|c|}
\hline Peak & Off peak & \\
\hline \multicolumn{3}{|c|}{5 min travel time response zones: population coverage } \\
\hline Statutory ambulance responses & 990991 & 1560917 \\
\hline $\begin{array}{l}\text { Statutory ambulance with only CFR } \\
\text { group responses }\end{array}$ & 1426648 & 2018446 \\
\hline $\begin{array}{l}\text { Statutory ambulance with all CFR } \\
\text { responses }\end{array}$ & 2043256 & 2619752 \\
\hline \multicolumn{3}{|c|}{10 min travel time response zones: population coverage } \\
\hline Statutory ambulance responses & 2405764 & 2802322 \\
\hline $\begin{array}{l}\text { Statutory ambulance with only CFR } \\
\text { group responses }\end{array}$ & 3114769 & 3433307 \\
\hline $\begin{array}{l}\text { Statutory ambulance with all CFR } \\
\text { responses }\end{array}$ & 3676177 & 3826063 \\
\hline
\end{tabular}



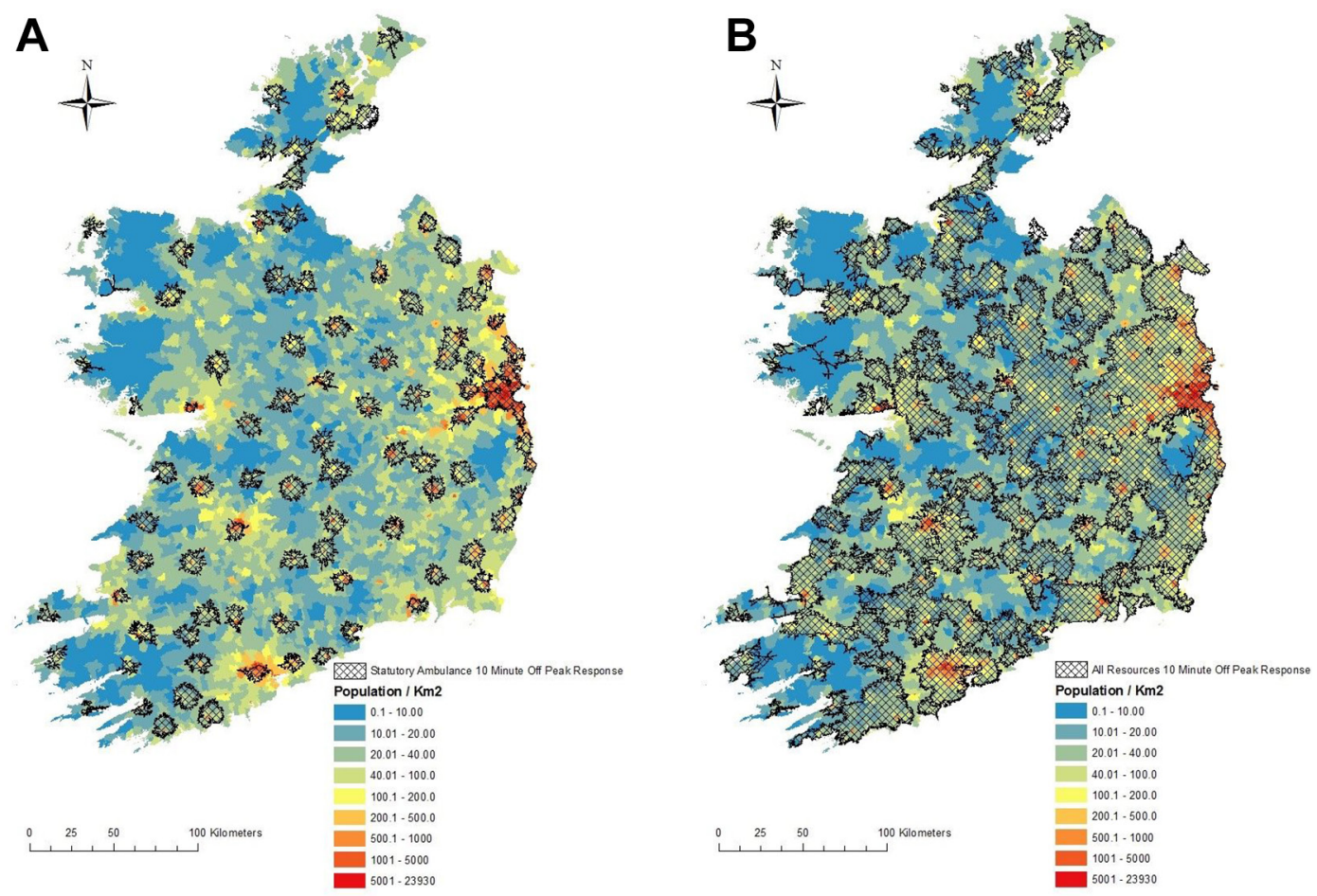

Figure 2 Ten-minute off-peak road travel response zones (statutory ambulance only). Ten-minute off-peak road travel response zones (all resources).

responders many areas of Ireland are unlikely to achieve a 10 min cardiac arrest response.

Figure 3 models the relative geographical contribution of the various types of community cardiac arrest response resources. Modelling was undertaken under off-peak conditions and considered a 10 min drive time response. The baseline statutory ambulance response zones are shown in green. The additional geographic coverage when group CFR schemes are added is shown in blue, and the further contribution of the addition of Individual CFRs is shown in purple.

\section{DISCUSSION}

In this study, we have used GIS mapping technology to describe a national system of community cardiac arrest response, to model the geographic distribution of CFRs and to consider their potential for timely OHCA response and impact at a population level. This is the first study to describe a national framework of community cardiac arrest response and to consider the geography of all potential OHCA responses in light of the population's geographic distribution. Although the mobilisation of CFRs to OHCA has been advocated as a health systems intervention on many levels and for some time in Ireland, ${ }^{22}{ }^{23}$ to date, there has been little published data to support this practice. Preliminary findings from the Merit 3 GP project showed the overall rate of survival to hospital discharge was similar to the national average. ${ }^{13}$ The findings of our modelling study suggest that the potential for CFR resources to add further value to statutory ambulance service responses is significant. Our results suggest that the 'full-capacity' availability of the current CFR structures allow a million additional citizens to come under the umbrella of timely OHCA emergency response. Crucially, volunteer CFRs may not always be available within their own communities at the key moment they may be required. Maximising this potential will require further resources and initiative.

The clinical interventions known to have most impact in improving survival following OHCA, namely early CPR and defibrillation, ${ }^{24}{ }^{25}$ have existed in mainstream medical practice, emergency medical services and public access defibrillation schemes for decades. ${ }^{26}{ }^{27}$ The recent innovation of real-time mobilisation of CFRs to OHCA is a significant additional development. It is a relatively low-cost additional intervention, founded on the fundamental interventions of CPR and defibrillation but ultimately a product of voluntarism and health system engagement among individuals and communities. Where CFRs can reach patients quickly, increased rates of survival can be achieved. ${ }^{28}$ The results of our study suggest that this potential currently exists for a large proportion of the population of Ireland who are otherwise unlikely to receive a timely statutory ambulance service OHCA response. What is not yet clear is whether the goodwill of volunteer CFRs in Ireland has been maximally optimised by the health system to ensure that CFRs are appropriately equipped and available to respond to OHCA when it occurs. An audit of CFR schemes in one region of Ireland showed that $47 \%$ of OHCA alerts 


\section{Relative Contribution of Community Resources 10 Minute, Off Peak}

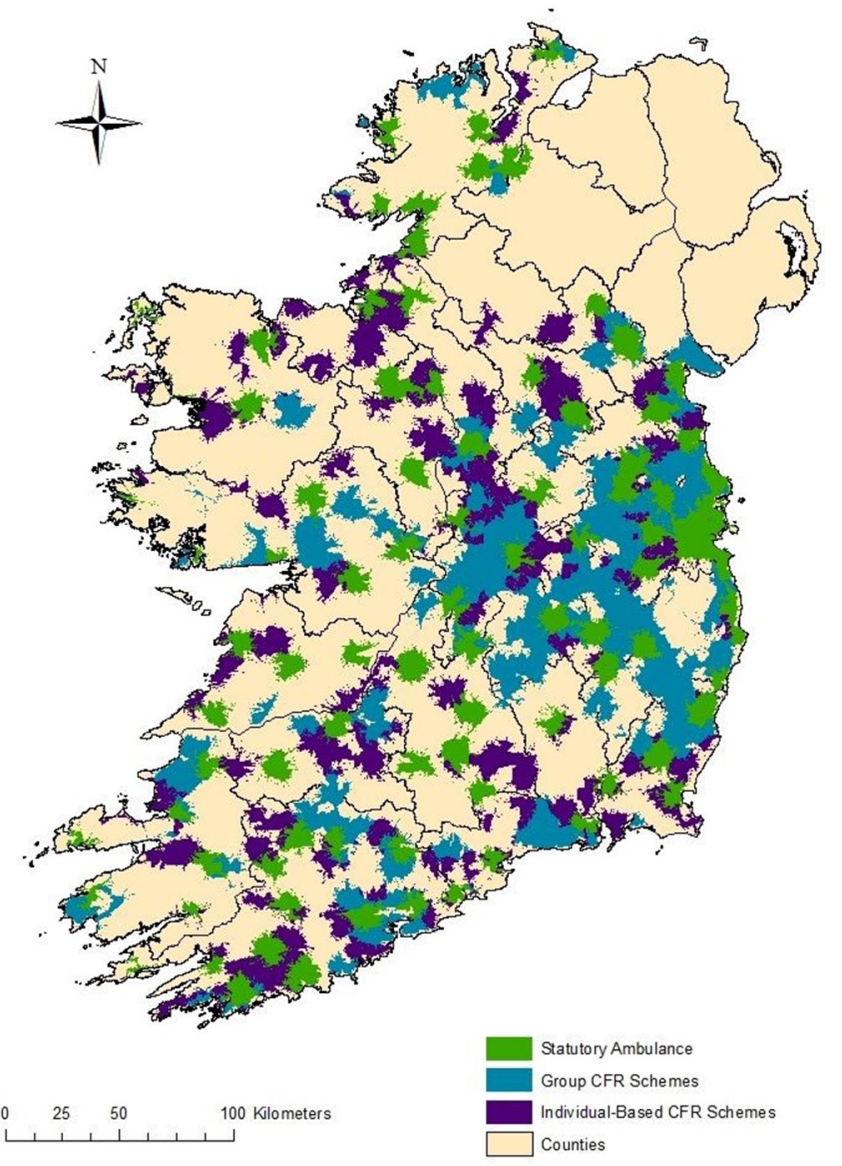

Figure 3 Relative geographical contribution of the various types of community cardiac arrest response resources. CFR, community first responder.

received a CFR response with a median response time of 8 min. ${ }^{29}$ Although the National Ambulance Service actively supports the development of CFR schemes, the fact that CFRs in Ireland currently receive minimal health system funding may warrant further consideration in this regard. Additional formalised health system support might facilitate the further development of CFR schemes and increase the likelihood of a capacity to respond to more OHCAs. The processes, experiences and outcomes of CFR involvement in OHCA resuscitation should be a priority for further research.

In addition to highlighting the potential impact of CFRs on survival, our results also suggest key challenges in achieving further timely OHCA emergency response population coverage. Many areas currently poorly served by the existing OHCA community responses appear to be of low population density. Our study did however highlight some areas of higher population density not currently served by timely community cardiac arrest resources. Although detailed analysis of individual smaller areas is beyond the scope of this current project, GIS mapping analysis could be conducted in more detail in focused areas and provide a basis for the development of OHCA response resources in those communities. GIS technology could also be used in other jurisdictions to examine community resources and to plan services.

\section{Limitations}

As a GIS computer modelling exercise, this study has important limitations that must be considered when interpreting its results. The ESRI AGOL proximity analysis drive time application creates travel time zones using historical and live electronic traffic data that ultimately models 'typical' traffic conditions and thus drive time durations in a given scenario. Statutory ambulance services respond to OHCA using lights and sirens and should in theory achieve shorter drive times than a computer model of typical travel times would predict. Given the significant data processing requirements of the research process, the model was run for one sample off peak and one sample peak time period, where in reality a degree of response time variability would be expected throughout the day and week. Our modelling exercise was based on travel from fixed point locations; however, neither ambulances nor CFRs are fixed-point resources. Both are mobile in the community and may be nearer or further from an OHCA event when alerted than the model accounted for.

In considering the populations served by various resources in a given time frame, there was unavoidably a degree of imprecision as census small area data do not identify the precise location of each individual and household. The model considered total populations of census small areas partially enclosed by the boundaries of drive time areas, which may overestimate coverage. For this reason, a sensitivity analysis with a proportional enclosed area population adjustment was included. As population distribution within a small area is likely to be related to that population's accessibility by road, the former approach was considered more appropriate for the primary model. The population data that have informed this study have considered populations based on their residential address and does not account for individuals who may commute outside a small area during the day for work purposes. In addition, the model considers the total population in a given area and does not adjust for population elements that are known to increase the risk of OHCA. It also assumes the 24/7 availability of CFRs. Furthermore, the $5 \mathrm{~min}$ and $10 \mathrm{~min}$ intervals do not consider the time required for the dispatch centre to identify OHCA, the time taken to go mobile (which may be longer for CFRs than for ambulance staff) and also the time from arrival on scene to reaching the patient. Finally, travel time information was not available for offshore island road networks relevant to four CFR schemes.

Despite these limitations, ESRI ArcGIS Desktop 10.4 and ESRI ArcGIS Online have proven useful tools in modelling what appears to be very significant potential for timely community OHCA response and population coverage when CFRs supplement the statutory ambulance 
service response. Given this potential, urgent prospective CFR research, considering real-world CFR and ambulance service resource availability, response times, clinical activity and outcomes is warranted to refine systems and achieve a meaningful increase in OHCA survival.

\section{CONCLUSION}

Volunteer OHCA responders are present in many communities throughout Ireland. They have the potential to reach a significant proportion of the population who are at risk of OHCA before the ambulance service and within a timeframe where CPR and defibrillation can save lives.

Acknowledgements The authors acknowledge the cooperation and support of the National Ambulance Service without whom this research would not have been possible.

Contributors All authors contributed to the design of the study. TB, JR and PW collected the data. TB and AG analysed the data.TB, SM and GB drafted the manuscript that was critically revised for important intellectual content by all authors. TB and GB are guarantors for the study.

Funding The authors have not declared a specific grant for this research from any funding agency in the public, commercial or not-for-profit sectors.

Competing interests None declared.

Patient consent Not required.

Ethics approval Exemption from full ethical review was obtained from the University College Dublin, Human Research Ethics Committee (LS-E-17-39-BarryBury).

Provenance and peer review Not commissioned; internally peer reviewed.

Data sharing statement There are no additional data available.

Open access This is an open access article distributed in accordance with the Creative Commons Attribution Non Commercial (CC BY-NC 4.0) license, which permits others to distribute, remix, adapt, build upon this work non-commercially, and license their derivative works on different terms, provided the original work is properly cited, appropriate credit is given, any changes made indicated, and the use is non-commercial. See: http://creativecommons.org/licenses/by-nc/4.0/

\section{REFERENCES}

1. CSO. Census 2016 summary results - part 1. Dublin: Central Statistics Office, 2017.

2. OHCAR. Out of hospital cardiac arrest register, annual report 2016. Galway: OHCAR, 2017

3. Nolan J, Soar J, Eikeland H. The chain of survival. Resuscitation 2006;71:270-1.

4. Deakin CD. The chain of survival: Not all links are equal. Resuscitation 2018;126:80-2.

5. Monsieurs KG, Nolan JP, Bossaert LL, et al. European resuscitation council guidelines for resuscitation 2015: section 1. Executive summary. Resuscitation 2015;95:1-80.

6. Perkins GD, Handley AJ, Koster RW, et al. European resuscitation council guidelines for resuscitation 2015: section 2. Adult basic life support and automated external defibrillation. Resuscitation 2015;95:81-99.

7. Hasselqvist-Ax I, Riva G, Herlitz J, et al. Early cardiopulmonary resuscitation in out-of-hospital cardiac arrest. N Engl J Med 2015;372:2307-15.

8. HIQA. Pre hospital emergency care key performance indicators for emergency response times. Dublin: HIQA; 2011, 2011. Available from: https://www.hiqa.ie/sites/default/files/2017-02/Pre_Hospital Emergency_Care_KPIs\%20(1).pdf [Accessed 28 May 2018].
9. Masterson S, Wright P, O'Donnell C, et al. Urban and rural differences in out-of-hospital cardiac arrest in Ireland. Resuscitation 2015;91:42-7.

10. Lightfoot. National ambulance service of Ireland emergency service baseline and capacity review. Berkshire, 2015.

11. HIQA. Review of pre-hospital emergency care services to ensure high quality in the assessment, diagnosis, clinical management and transporting of acutely ill patients to appropriate healthcare facilities. Dublin: HIQA; 2014, 2014. Available from: https://www.hiqa.ie/sites/ default/files/2017-01/HIQA-Ambulance-Review-Report-2014.pdf [Accessed 28 May 2018].

12. Barry T, Conroy N, Masterson S, et al. Community first responders for out-of-hospital cardiac arrest. Cochrane Database Syst Rev 2017;67.

13. Barry T, Conroy N, Headon M, et al. The MERIT 3 project: alerting general practitioners to cardiac arrest in the community. Resuscitation 2017;121:141-6.

14. Hansen CM, Kragholm K, Granger CB, et al. The role of bystanders, first responders, and emergency medical service providers in timely defibrillation and related outcomes after out-of-hospital cardiac arrest: results from a statewide registry. Resuscitation 2015;96:303-9.

15. Smith LM, Davidson PM, Halcomb EJ, et al. Can lay responder defibrillation programmes improve survival to hospital discharge following an out-of-hospital cardiac arrest? Aust Crit Care 2007;20:137-45.

16. Ringh M, Rosenqvist $\mathrm{M}$, Hollenberg J, et al. Mobile-phone dispatch of laypersons for CPR in out-of-hospital cardiac arrest. N Engl J Med 2015:372:2316-25.

17. Phung VH, Trueman I, Togher F, et al. Community first responders and responder schemes in the United Kingdom: systematic scoping review. Scand J Trauma Resusc Emerg Med 2017;25:58.

18. Phung VH, Trueman I, Togher F, et al. Perceptions and experiences of community first responders on their role and relationships: qualitative interview study. Scand J Trauma Resusc Emerg Med 2018;26:13.

19. CSO. Census 2016 small area population statistics. Secondary census 2016 small area population statistics 2016, 2016. Available from: http://www.cso.ie/en/census/census2016reports/census20 16smallareapopulationstatistics. [Accessed 28 May 2018].

20. CSO. Census 2016 Boundary files. Secondary census 2016 boundary files. Dublin: CSO; 2016, 2016. Available from: http://www. cso.ie/en/census/census2016reports/census2016boundaryfiles/ [Accessed 28 May 2018].

21. ESRI. ArcGIS online directions and routing services coverage. Available from: http://www.arcgis.com/home/item.html?id=b7a893e8 e1e04311bd925ea25cb8d7c7 [Accessed 28 May 2018].

22. Department of Health \& Children. Reducing the risk: a strategic approach : the report of the task force on sudden cardiac death. Dublin: Department of Health and Children, 2006.

23. HIQA. Health technology assesment of public access defibrillation. Dublin: HIQA; 2014, 2014. Available from: https://www.hiqa.ie/ sites/default/files/2017-01/HTA-of-Public-Access-Defibrillation.pdf [Accessed 28 May 2018].

24. Blom MT, Beesems SG, Homma PC, et al. Improved survival after out-of-hospital cardiac arrest and use of automated external defibrillators. Circulation 2014:130:1868-75.

25. Rajan S, Wissenberg M, Folke F, et al. Association of bystander cardiopulmonary resuscitation and survival according to ambulance response times after out-of-hospital cardiac arrest. Circulation 2016;134:2095-104.

26. Cooper JA, Cooper JD, Cooper JM. Cardiopulmonary resuscitation: history, current practice, and future direction. Circulation 2006; 114:2839-49.

27. Hallstrom AP, Ornato JP, Weisfeldt M, et al. Public-access defibrillation and survival after out-of-hospital cardiac arrest. N Engl J Med 2004;351:637-46.

28. Pijls RW, Nelemans PJ, Rahel BM, et al. A text message alert system for trained volunteers improves out-of-hospital cardiac arrest survival. Resuscitation 2016;105:182-7.

29. O' Toole A. A retrospective analysis and description of the workload of NAS deployed CFR Scheme in Co. Wicklow. MSc Thesis. Dublin: University College Dublin, 2015. 